SIDE EFFECTS OF DRUGS

\section{Prazosin: the first-dose phenomenon}

There have recently been several reports of ill-defined adverse reactions after initial exposure to prazosin hydrochloride. ${ }^{1-5}$ These include collapse and loss of consciousness; palpitations; feelings of unreality, light-headedness, and dizziness; and the rapid onset of lassitude, weakness, and diarrhoea. On the basis of single-case reports and uncontrolled observations in small groups of patients, these reactions seem to result from acute hypotension and tachycardia ${ }^{4}$ occurring in a few (2-9\%) patients. ${ }^{6}$ ?

We report the preliminary findings of a controlled study designed to investigate the early haemodynamic and pharmacokinetic properties of prazosin, the prevalence of the "first-dose phenomenon," and the means of preventing it.

\section{Patients and methods}

Six unselected hypertensive volunteers (four men and two women) aged 27 to 61 were studied in a metabolic ward after three days' stabilisation. Detailed investigations showed essential hypertension without renal impairment in five and renal hypertension (with a stable serum creatinine level of $265 \mu \mathrm{mol} / 1(3.0 \mathrm{mg} / 100 \mathrm{ml}))$ in one. All patients received a diet containing
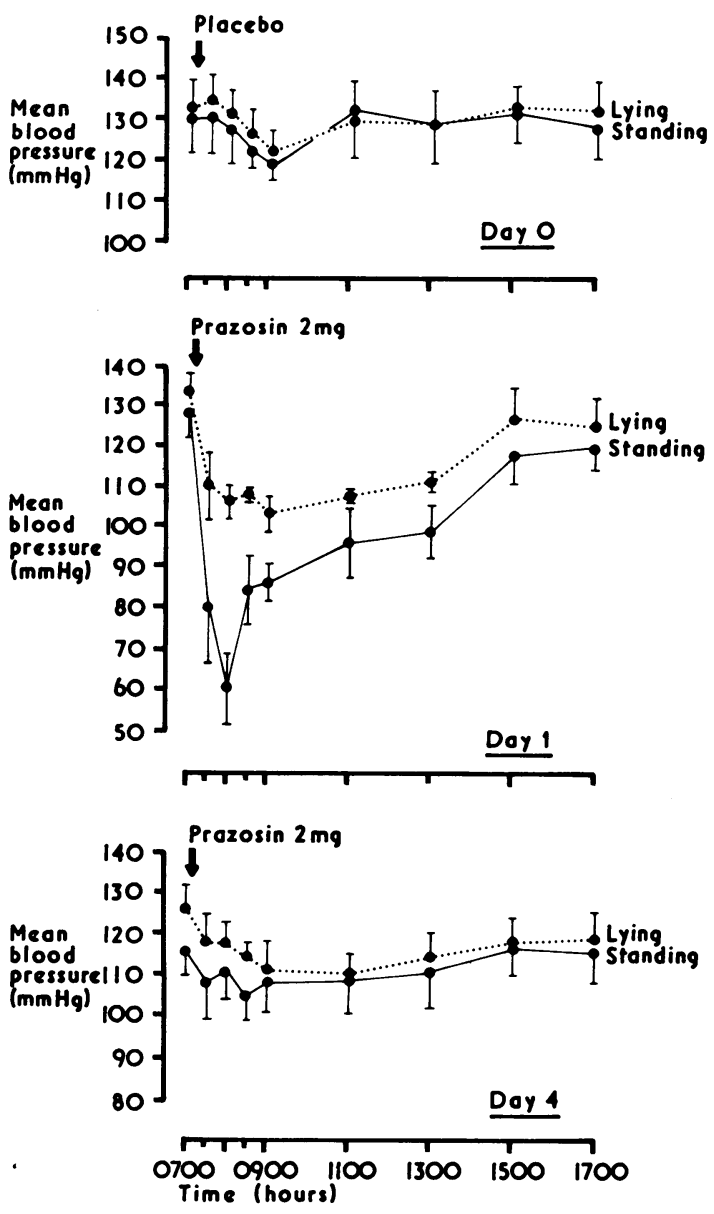

Responses in mean blood pressure of six hypertensive patients to placebo tablet (day 0 ) and to 2-mg prazosin tablet, given as the first dose (day 1) and as test dose (day 4). On days 2 and 32 -mg prazosin was administered three times a day.
$100 \mathrm{mmol}$ (mEq) sodium/day throughout the study. Two patients had not been treated, and one had stopped all drugs, including prazosin, four weeks before the study. Three patients were receiving propranolol (mean dose $=$ $267 \mathrm{mg} /$ day) and two also a thiazide diuretic; doses had been stable for at least a month before the study.

Control study (day 0) - At 0700 blood pressure and heart rate were recorded in the supine and erect positions before and immediately after an exercise stress test. The patients then received a placebo tablet, and blood pressure and heart rate recordings continued every half hour until 0900 , then every two hours until 1700 .

Treatment study (days 1 to 4 )-On days 1 and 4 prazosin $2 \mathrm{mg}$ was given by mouth at 0700 after an overnight fast, and blood pressure and heart rate were monitored as on day 0 . Before each observation blood samples $(5 \mathrm{ml})$ were also collected for measuring plasma prazosin levels. On days 2 and 3 the patients received prazosin $2 \mathrm{mg}$ orally at 0700,1500 , and 2300 .

Techniques. Blood pressure was recorded using the same standard clinical mercury sphygmomanometer for each patient, the 5th phase of Korotkoff sounds being used to determine the diastolic pressure. Mean blood pressure was derived by adding one-third of the pulse pressure to the diastolic blood pressure. The exercise stress test involved stepping up and down a $40-\mathrm{cm}$ step for 1 minute, at a readily tolerated rate which was kept constant for each patient. The rate was 20 steps/min (equivalent to a workload of 600 kpond $\mathrm{m} / \mathrm{min}$ ) for four patients and 15 and $5 \mathrm{steps} / \mathrm{min}$ for the other two patients. Plasma prazosin was assayed spectrofluorimetrically. ${ }^{8}$ Statistical analysis was performed by Student's paired $t$ test, results being expressed as the mean $\pm 1 \mathrm{SE}$.

\section{Results}

The figure shows the blood pressure responses to a placebo tablet (day 0), an initial 2-mg oral dose of prazosin (day 1), and a subsequent challenge with $2 \mathrm{mg}$ prazosin administered after two days of treatment with prazosin three times a day (day 4). After the placebo the mean blood pressure remained constant except for an insignificant $10-\mathrm{mm} \mathrm{Hg}$ fall at 0900 . Within 30 minutes of the administration of the 2-mg tablet of prazosin (day 1) there was a significant fall in lying blood pressure and a much steeper fall in standing pressure. These responses were greatest after one to two hours, when they were highly significant $(P<0.002$ and $P<0.005$ respectively).

Mean $( \pm 1 S E$ ) heart rate (beats/min) of six hypertensive patients in relation to administration of placebo tablet (day 0 ) or 2-mg oral prazosin given before (day 1) and after (day 4) two days of continuous prazosin treatment

\begin{tabular}{|c|c|c|c|c|c|c|}
\hline & & & & & $\begin{array}{c}\text { Control values } \\
(0700)\end{array}$ & $\underset{(0900)}{\operatorname{Maximal} \text { response }}$ \\
\hline $\begin{array}{l}\text { Day 0: } \\
\text { Lying } \\
\text { Standing }\end{array}$ & $\because$. & . & $\because$ & $\because$ & $\begin{array}{l}70 \pm 5 \\
87 \pm 6\end{array}$ & $\begin{array}{l}76 \pm 6 \\
87 \pm 7\end{array}$ \\
\hline $\begin{array}{l}\text { Day } 1: \\
\text { Lying } \\
\text { Standing }\end{array}$ & $\ddot{*}$ & $\because$ & $\because$ & $\because$ & $\begin{array}{l}78 \pm 4 \\
89 \pm 5\end{array}$ & $\begin{array}{r}89 \\
111 \pm 6^{*}\end{array}$ \\
\hline $\begin{array}{l}\text { Lying } \\
\text { Standing }\end{array}$ & $\because$. & $\because$ & $\because$ & $\because$ & $\begin{array}{l}75 \pm 5 \\
90 \pm 6\end{array}$ & $\begin{aligned} 83 & \pm 7 \\
107 & \pm 6 \dagger\end{aligned}$ \\
\hline
\end{tabular}

Effect significantly different from placebo response: ${ }^{*} \mathrm{P}<0.005 ; \uparrow \mathrm{P}<0.05$.

The change in mean blood pressure was still significantly different from the placebo response at $1300(P<0.02$ lying and $P<0.01$ standing $)$ but had returned almost to control levels by 1700 . At the time of the greatest response five of the subjects felt faint and could not do the exercise stress test. The remaining subject became faint after exercise. Two patients complained of nausea and malaise, and one developed central chest pain which rapidly subsided when she lay down and was not associated with electrocardiographic changes. On day 4 a single $2-\mathrm{mg}$ dose of prazosin caused a slow fall in blood pressure, which was significantly different from the placebo response only at 1100 ( $P<0.01$ lying and $P<0.05$ standing). All patients remained asymptomatic and at all times could perform the exercise stress test.

Mean heart rate responses are summarised in the table. After the placebo there was no significant change from the baseline values at 0700 . On day 1 there was a rise in lying and standing heart rate that coincided with the antihypertensive response. On day 4 there was a transient rise in standing heart rate, but no change in lying heart rate. 
Plasma prazosin was measured in five patients. In the four with normal renal function there was close agreement between plasma prazosin concentrations at corresponding times; also, the mean values were consistently higher on day 4 than on day 1 at each observation from 0730 to 1700 $(P<0.05)$. Peak plasma prazosin levels averaged $14.9 \pm 3.5 \mathrm{ng} / \mathrm{ml}$ on day 1 and $26.8 \pm 1.8 \mathrm{ng} / \mathrm{ml}$ on day 4 . These levels coincided with the maximal antihypertensive response on day 1 but preceded the maximal response on day 4. Plasma levels in the fifth patient who had renal impairment were much higher (peak level $31.6 \mathrm{ng} / \mathrm{ml}$ on day $1 ; 80.5 \mathrm{ng} / \mathrm{ml}$ on day 4 ).

\section{Comment}

After the introduction of prazosin $2 \mathrm{mg}$ all patients developed a strong antihypertensive response associated with severe postural hypotension and significant tachycardia. These effects had almost disappeared after the second 2-mg tablet on day 2, although adverse effects persisted until the second day of continuous prazosin therapy (day 3) in two patients. By day 4 all patients were asymptomatic even after the exercise stress test, while the antihypertensive effect was only marginally greater than the placebo response. Furthermore, the lying heart rate remained stable compared with the placebo response, while standing heart rate rose only transiently.

Adverse effects may have been exaggerated in this study because (a) all patients were in balance on a diet that probably contained less sodium than the average diet of our hypertensive population, and (b) three of the patients, who were also receiving a beta-blocking agent and a diuretic, had a stronger and more persistent response. Nevertheless, our findings suggest that all patients, if sufficiently stressed, may show symptomatic postural hypotension after the introduction of prazosin at the $2-\mathrm{mg}$ dose level.

The uniformity of the response in our patients and a report of similar but more profound and sustained postural hypotension after a 5 -mg dose of prazosin to normotensive subjects ${ }^{9}$ suggest that this effect may be dose-related rather than idiosyncratic. Further studies are being undertaken to investigate the responses after smaller doses of prazosin. Our preliminary findings indicate that appreciable first-dose effects, less severe and shorter than those reported above, still occur after $0.5 \mathrm{mg}$.

As prazosin is extensively metabolised in the liver in rats and dogs (Pfizer, unpublished observations), plasma levels were measured to investigate the possibility that the first-dose phenomenon results from initial high concentrations of prazosin which subside with continued treatment, owing perhaps to enhanced drug metabolism, such as that resulting from induction of hepatic enzymes. Our results clearly indicate that the reaction cannot be explained on this basis, for in all cases the response had subsided by day 4 despite the presence of much higher plasma drug levels.

The finding of exceptionally high plasma levels of prazosin in a single patient with renal impairment but without clinical or biochemical evidence of hepatic disease agrees with the observation of Collins et al. ${ }^{8}$ Unlike their patient, however, ours was not receiving a beta-blocking drug.

We conclude that the first-dose phenomenon is due to severe symptomatic postural hypotension which rapidly subsides with protracted treatment and may be dose-related. It is therefore advisable to start treatment with a dose of $0.5 \mathrm{mg}$ or less, particularly in patients who are already receiving beta-blocking drugs or who may be relatively sodium-depleted as a result of previous diuretic treatment.

This work was supported in part by grants from the Laura Bushell Trust and the National Heart Foundation of Australia. We thank Dr W Gunner of Pfizer Ltd, for supplies of prazosin.

Requests for reprints should be addressed to Dr G S Stokes, Cardiorenal Unit, Medical Research Department, Kanematsu Memorial Institute, Sydney Hospital, Sydney, NSW 2000, Australia.

${ }^{1}$ Bendall, M J, et al, British Medical fournal, 1975, 2, 727.

2 Gabriel, R, et al, Lancet, 1975, 1, 1095.

3 Rees, J, et al, British Medical fournal, 1975, 3, 593.

4 Seedat, Y K, et al, British Medical fournal, 1975, 3, 305.

5 Committee on Safety of Medicines, Adverse Reactions Series No 12. London, DHSS, 1975.
${ }^{6}$ Hayes, J. M, et al, Medical Fournal of Australia, 1976, 1, 562.

${ }^{7}$ Meek, D, et al, Current Medical Research and Opinion, 1976, 3, 672.

${ }^{8}$ Collins, I S, et al, Clinical and Experimental Pharmacology and Physiology 1975, 2, 445.

${ }^{9}$ Wood, A J, et al, British fournal of Clinical Pharmacology, 1976, 3, 199.

Cardiorenal Unit, Medical Research Department, Kanematsu Memorial Institute, Sydney Hospital, Sydney, NSW 2000, Australia R M GRAHAM, MB, BS, fellow in cardiorenal diseases

I R THORNELL, BSC, scientific officer

J M GAIN, SRN, SRM, research nurse

C BAGNOLI, BSC, research assistant

H F OATES, BSC, PHD, senior scientific officer

G S STOKES, MD, FRACP, cardiorenal physician

\section{Local gold toxicity}

With the growing use of gold salts in the treatment of rheumatoid disease there will no doubt be increasing reports of the rarer side effects related to its administration. ${ }^{1}$ The more readily avoidable toxic reactions should, however, not be forgotten.

\section{Case report}

A 51-year-old Glaswegian housewife had had progressive, seropositive, nodular rheumatoid disease for one year when she was referred for chrysotherapy, having undergone routine screening investigations. These showed a normal platelet count and normal urine analysis. She said that she had had no generalised rashes. She weighed $55 \mathrm{~kg}$.

Treatment-She was given a test dose of $10 \mathrm{mg}$ intramuscular sodium aurothiomalate (Myocrisin) as an outpatient and told to continue with ibuprofen $400 \mathrm{mg}$ four times a day and paracetamol as required. This was her total medication.

Adverse effects-About eight hours after starting gold treatment the patient experienced mild irritation of the left ring finger, necklace area, and earlobes, and, on review 24 hours after the initial injection, there was obvious swelling and pustulation of the affected regions. Further questioning showed that a gold wedding ring worn continuously for 27 years and gold earrings worn intermittently for 10 years had had to be discarded at the onset of the rheumatoid disease because of contact dermatitis. Interestingly, the patient denied wearing a gold necklace. There was no personal or family history of adverse drug reaction, and limited investigations showed a normal platelet count, normal white blood cell and differential counts, and normal urine analysis. The signs and symptoms settled in a fortnight after the topical application of betamethasone.

\section{Comment}

Specific questions about local gold toxicity were omitted before the test dose of gold was given. The patient had not considered the relevance of local gold toxicity to gold injections and did not mention her previous experience. Clinicians should not forget to ask the basic question about local gold toxicity. It is also our experience that patients on established chrysotherapy are unwilling to report minor skin reactions spontaneously for fear of treatment being withdrawn. Patients are therefore specifically asked about such reactions at each attendance.

${ }^{1}$ Geddes, D M, and Brostoff, J, British Medical fournal, 1976, 1, 1444.

Centre for Rheumatic Diseases, Baird Street, Glasgow G4

J A N RENNIE, MD, MRCP, honorary senior registrar 